\title{
Chapter 16 \\ Stray Agency and Interspecies Care: \\ The Amsterdam Stray Cats and Their \\ Humans
}

\author{
Eva Meijer
}

\begin{abstract}
This chapter discusses the Stichting Amsterdamse Zwerfkatten (Amsterdam Stray Cat Foundation, afterwards SAZ), who work with and for stray cats. In their practices and views they challenge common assumptions about cat subjectivity and agency, the cats' right to a habitat and social relations, as well as the idea that there is a strict difference between cats and humans. Their approach offers an alternative way of thinking about cat agency and human agency, networks of cathuman relations, sharing the city with cats, and working towards more freedom for cats and humans. In the chapter I examine these relations from the perspective of agency, care, and politics, and investigate whether or not this can function as a model for building new communities with other animals, which centres their agency.
\end{abstract}

\subsection{Introduction}

Invisible to most, Amsterdam is home to many stray cats. These cats are neither wild nor domesticated: they live close to humans but usually do not depend on them. ${ }^{1}$ Depending on their location and the humans in that area, their living circumstances can be anywhere on a spectrum between fairly precarious and fairly comfortable. Their lives may be more dangerous than those of companion cats, yet they also experience a larger degree of freedom, understood not only as the capacity to roam freely but also to make choices about where to live and with whom, and more generally how to lead one's life. Still, it is often assumed that companion cats are better off than stray or feral cats, and that cats living on the streets should be rescued, neutered and adopted by humans (Srinivasan 2013). Because they challenge dualisms between

\footnotetext{
${ }^{1}$ I use the word stray instead of feral or semi-feral to translate the Dutch 'zwerfkatten', which can refer to abandoned house cats, semi-feral and feral cats.
}

E. Meijer $(\varangle)$

Wageningen University and Research, Wageningen, The Netherlands

e-mail: eva1.meijer@wur.nl

B. Bovenkerk and J. Keulartz (eds.), Animals in Our Midst: The Challenges

of Co-existing with Animals in the Anthropocene, The International Library

of Environmental, Agricultural and Food Ethics 33,

https://doi.org/10.1007/978-3-030-63523-7_16 
nature and culture, domesticated and wild, many humans see them as out of place, or as not really belonging in the city (Van Patter and Hovorka 2018). They do not belong to a human, as domesticated animals do, but are also not understood as native to a certain area, such as for example deer or songbirds. Most of the Amsterdam stray cats are descendants of house cats from Amsterdam, who carved out their own lives in the city, have learned to negotiate its risks, and built relationships with one another. Assumptions about these cats as either belonging or not belonging in the city, and about human duties towards them, are usually based on the view that cats, like other animals, are categorically different from humans and that humans are hierarchically above them. The city belongs to the humans who built it, and other animals are seen as companions, guests or pests, but, perhaps with the exception of songbirds, not as rightful inhabitants. Interconnected with this is the fact that the cats, as other nonhuman animals, have no formal legal or political rights.

In this chapter I discuss the work of the Stichting Amsterdamse Zwerfkatten (Amsterdam Stray Cat Foundation, afterwards SAZ), who work with and for stray cats. In their practices and underlying ideals they challenge common assumptions about cat subjectivity and agency, their right to a habitat and social relations, as well as the idea that there is a strict difference between cats and humans. They emphasize cat agency, and have a non-anthropocentric view to cat-human relations, which shows us new ways of sharing the city with cats, and working towards more freedom for cats. I volunteered at the SAZ for a year and his paper is based on informal conversations with other volunteers and members of staff, written statements from the website of the SAZ (www.saz.amsterdam) and their biannual magazine Swieber, and my observations of cat-human interactions.

My aim in this chapter is not to provide a theory of just cat-human relations, or to develop a cat ethics for the Anthropocene. The chapter should be understood as a case study that draws on insights from political philosophy, ecofeminism and animal studies more broadly, to investigate what happens at the SAZ, and how their practices and views relate to mainstream ideas and practices. I focus specifically on agency and interspecies relations. In the first section I discuss the work of the SAZ in more detail. Section two zooms in on agency, discussing stray cat and human volunteer agency, and interconnections between these. The third section builds on these ideas about agency and relationality and turns the focus to interspecies care at the SAZ, and in the city of Amsterdam. In section four I move to the politics of the SAZ and the Amsterdam stray cats. The conclusion investigates what lessons we can learn from cat-human relations at the SAZ, in the context of establishing better relations with the other animals with whom we share our cities and households.

\subsection{The Amsterdam Stray Cat Foundation}

The SAZ have been working for and with the stray cats in and around Amsterdam since 1994. They 'trap, neuter and return' (TNR) the cats who are too wild to adjust to a life in a human home, and they socialise those who show interest in interacting with 
humans. Once these cats are used to humans, they are taken to shelters in the area from where they can be adopted. The SAZ also assist stray cat colonies in the city, making sure they are fed and watched, and receive healthcare if needed. They make sure all TNR cats are looked after when they are released back into their habitats, and they provide help for humans who take care of stray cats in their gardens or in parks near their homes by supplying food and winter homes, so called iso-boxes, for the cats.

They focus not only on stray cats: a large part of their work is offering financial support to humans who cannot afford veterinary care for their cats. In this context they also offer more general help to humans and cats in need, and are a last resort especially for those who need immediate help. They for example provide shelter for cats in cases of domestic abuse, or take over their medical treatment if their humans cannot provide the appropriate care. They also started a food bank for companion animal food. Those practices are documented in a biannual magazine and on social media, aimed at promoting better cat-human relations, and often drawing attention to the cats' perspectives on matters. They influence city policies with regard to dealing with stray cats, and developing neutering programs.

When the SAZ started in 1994, there were many genuinely feral cats in Amsterdam. Currently, most of the cats on the streets are either lost or abandoned, which is largely because of their TNR work and neutering programs. The SAZ see neutering companion cats as the most efficient way of reducing stray cat suffering, and run campaigns to convince humans to neuter their cats. In these and other efforts, they treat humans similar to the cats, sometimes adopting a slightly paternalistic attitude: humans need to be educated and/or nudged into having their cats neutered and taking good care of them. This attitude is also adopted with regard to financial help with medical issues. In summer, cats often fall from balconies, because they are playing or chasing birds or insects, or because they are old, or simply make a mistake. The SAZ will take care of these cats when necessary and pay for medical bills, but they will also visit the house and check if the balcony is fenced before humans get their companions back.

The SAZ receive a small amount of money from the municipality for their TNR program and neutering campaigns; the remainder of their activities are paid for by private donations and funding from animal welfare organisations. Only two of the humans who work at the SAZ are paid, both receiving the minimum wage. One of these humans cleans the cages, and the other is in charge of daily management. Most of the work however, including cleaning, socializing cats, administration, driving on the ambulance, and catching cats, is done by volunteers. Many of these volunteers have 'a backpack' as the Dutch say, usually referring to psychiatric problems, though some have physical disabilities as well.

I applied for a cleaning job at the SAZ after my cat companion Putih died in the summer of 2016, and was soon promoted to the office, where I answered phone calls, did administrative work, and applied for funding. In the year I worked at the SAZ, I got to know the other humans who worked on Tuesdays quite well, as well as some of the cats who stayed in the socialization kennels for a longer period of time. I was struck by the attention for cat agency I witnessed, and found out there are many 
invisible networks of care in the city of Amsterdam, formed by humans who look after stray cats, and often vice versa.

\subsection{Degrees of Agency}

Cat agency plays a major role in how the SAZ functions, both with regard to human behaviour and with regard to how different procedures are set up. ${ }^{2}$ Catching cats, taking care of them afterwards, socialising the ones who show they want be socialised, releasing the others; all of this is done in ways that the cats co-determine, even though the power relations are not equal.

With feral and stray cats this works as follows. Before cats are caught, they are usually fed for a while at a certain time, in a certain place-both of which the cats codetermine. The cats are then caught, either because they allow humans to touch them, or, usually, by placing a cage at the feeding place. After they are caught they are taken to the SAZ headquarters, where they receive a health check and are neutered, and then are monitored for a while to see if they show interest in socialization. Sometimes it is immediately clear that they do not-experienced volunteers have developed an eye for it - at other times this needs more time. Cats often determine working hours of SAZ' volunteers, and of humans feeding cats, as well as cleaning techniques, and other SAZ procedures.

Cat agency also influences the lives of humans caring for them in the city. Many of the humans who call for assistance have adapted to having cats living in their gardens, and are willing to put great effort into caring for them or helping them. The cats brought them in this position: they normally take the first step in the relation by choosing a place to live, and picking specific humans to interact with.

While cat agency is taken seriously by the SAZ-paying attention to and respecting cat agency is one of the first things new volunteers learn-, cats have no official rights, and their political voice is not recognized by larger society. There is a gap between recognition of their agency at the micro-level, and official institutions and procedures. This is not a matter of all or nothing: cat agency, for example, does influence interaction with the city council from a distance, because of the habitats that the cats choose, and through the humans who advocate for them. They are informed and influenced by their relations, and sometimes negotiations, with the cats.

Nevertheless, the cats have no real voice in many of the decisions that concern their lives. Interestingly, many of the humans volunteering at the SAZ experience the same. They often complain that they do not speak the language of official institutions, which may lead to problems in their personal lives, and can also affect the effectiveness of their advocacy for the cats. In fact, many of them are more fluent in 'cat language' than in formal Dutch. This is partly due to a class difference: most volunteers at the SAZ have received no higher education and come from poor backgrounds, in contrast

\footnotetext{
${ }^{2}$ For similar observations, see Alger and Alger (1997, 2003).
} 
to volunteers who work for private funds and government employees. It is also due to their neurodiversity. Many volunteers identify as autistic, having personality disorder, suffering from depression, or simply as 'crazy'. While their different perspectives sometimes lead to conflicts between volunteers, or between SAZ volunteers and outsiders, it also provides the organisation with valuable knowledge about groups of humans that are seen and treated as difficult by other organisations and official institutions. In fact, one of the great strengths of the SAZ is that they assist humans from marginalized groups, such as for example animal hoarders, psychiatric patients, incarcerated people, victims of domestic violence, and homeless people, if they need temporary or permanent help with their companions, offering shelter or medical care. These humans are often not too eager to interact with official institutions such as governmental organisations or even larger animal welfare organisations, but they trust the humans at the SAZ, or come to trust them after a while.

Humans have certain advantages in anthropocentric societies, but not all humans have them to the same degree. ${ }^{3}$ At the SAZ there are many different relations between humans and cats, in which humans and cats exercise agency, and have their specific strengths and weaknesses, some of which are connected to being part of a specific social group, while others are individual. With agency I do not refer to the Kantian rational interpretation of this concept, but neither to object-oriented positions (Bennett Benett 2010; Latour 1993): it should be understood as relational and situated. Cats and humans enable each other to act in certain ways, and influence one another in a variety of ways (see also Bovenkerk and Meijer in this volume).

\subsection{Networks of Care}

Human care plays an important role in the lives of many of the stray cats. Outside cats are provided with food and healthcare, which is especially important when they get older. Cats in the socialization program receive quite a lot of care when they are at the SAZ, which continues after they are adopted. Kittens sometimes require intensive medical care, and they are usually placed in foster families.

The cats also take care of humans. Stray cats can provide their chosen humans with responsibility, a goal in life, mutual habits, and often also company, as many do at some point connect with the humans (often elderly females, sometimes males) who care for them. The volunteers who work at the SAZ have similar experiences. Cats interact with them, which leads to special relations with certain humans. ${ }^{4}$ Caring for cats can for certain humans be helpful in itself. Being a volunteer creates a responsibility, and asks for them to be physically present, which means getting out of bed and going to the SAZ. The daily manager of the SAZ plays an important role

\footnotetext{
${ }^{3}$ See Taylor (2017) for a broader discussion of the interconnections between constructions of disabilities and animality.

${ }^{4}$ These cats are usually not cute at all, they often do not like humans, cannot be touched or approached, which can make the care difficult and demanding, but rewarding as well.
} 
in this. If someone is for example depressed and in bed all day, she will call them and ask to bring in fish for a cat that has trouble eating. Humans will often feel obliged to come in for a specific cat, or because the cats generally need them. This can make a large difference in the lives of individuals. In casual conversations about the cats and their role in their lives, they often express feeling a special connection to the cats because they are outsiders too.

The SAZ also creates a culture of care, which transcends individual interactions. This is perhaps most visible at the SAZ headquarters, where volunteers are taught how to care for cats, through education and written rules, and cats learn to care for humans and one another. Care is not just feeding cats or keeping them safe. It can also involve play, for example. Younger cats especially often begin their contact with humans in the form of play-touching comes later. Similarly, black humour is for the humans an important tool in dealing with hardships in their own lives and the cats' lives. This culture is also found outside of the SAZ headquarters, in the network of humans who care for stray cats in the city. Not only do individuals take care of the cats, they know one another and work together to provide this care. They keep an eye on neighbourhood cats who have homes and make sure they are treated well, and they keep an eye on each other. The cats of course also form communities, in which they sometimes care for one another. Females in colonies for example sometimes share the care for kittens, including nursing.

Building on care ethical views Lori Gruen (2015) argues that there is a normative component to our entanglements with other animals: in order to do justice to those that we are connected to, we have to develop a kind of caring perception-an entangled empathy - that is focused on attending to the wellbeing of others. Developing empathy in this manner is a process in which both cognition and emotion have a role to play. With stray and feral cats one needs to pay attention, because otherwise you can get scratched or worse, and at the SAZ their perspective is brought to the front. Humans who start working there learn to be perceptive from the other humans, and from the cats; new cats learn from other cats and humans. Humans are often seen as givers of care, and other animals as recipients of care. The SAZ show that this is not necessarily the case, and that there are many different types of relationships possible. Recognizing that humans and cats at certain times depend on the other challenges a binary opposition between humans on the one side and cats on the other, with regard to agency and care. At the SAZ cats and humans are treated similarly: they are taken seriously as individuals, and attended to in special ways if necessary.

\subsection{Cat Politics}

The political position of the Amsterdam street cats is currently ambiguous. They are treated better than certain other inhabitants of the city, such as rats or pigeons, and perhaps even certain humans groups, such as illegalized refugees. Cats have a better reputation than pigeons or rats, who have traditionally been negatively stereotyped and are often unjustly associated with disease (see Meijboom and Nieuwland in this 
volume). Many humans more or less accept the cats' presence, and often do not even notice them. When there are problems, education can play a role: once humans learn that cat colonies are looked after and the cats are neutered, they tend to accept them. At the same time however the cats do not have political or legal rights, similar to other nonhuman animals, which makes their situation precarious and means they depend on the goodwill of humans for fair treatment. While current legislation in the province of Noord-Holland favours TNR over killing stray cats, this is up for debate in other provinces and could change.

The SAZ' attitude towards the cats reflects this ambiguity. Cat subjectivity is taken seriously — all cats are treated equally and seen as worthy of care and consideration-, and cats are treated as social beings who should have a place to live, opportunity to form relations with others, and lead a life that is good for them. They however do not argue for cat rights, and the cats' rights to life, bodily integrity, and autonomy are not always recognized, which seemingly contradicts their commitment to cat agency and subjectivity. This is most visible in their approach to euthanasia and neutering.

Older TNR cats who have lived in a certain habitat for a long time often depend on one human to take care of them. When this human dies and there is no one to take over the care, euthanizing, or, less euphemistically, killing, the cats is sometimes considered to be the best option. Old cats usually cannot settle in a new territory because they are too fragile, or be adopted by humans, because they are too wild. Living at the SAZ causes them great distress, and while this can be a temporary solution, it is not a permanent one. Similar problems arise with cats who are ill and need long-term treatments, who are permanently injured, or who have long hair, and who are too afraid of humans to live with them. Ideally, cats from these groups should have the chance to move into cat villages, where they can live at a distance from people but are regularly checked on by humans who have experience with wild cats. There are however not enough spaces in these cat villages for all cats, and when the waiting lists are long, older cats are sometimes killed. In the case of humans we would find this unacceptable, and create spaces where they could stay. This is of course part of a larger framework in which nonhuman animals' lives are not valued in the same way as human lives, but the SAZ are an actor in this system.

Another example of violating cats' bodily integrity and autonomy is neutering. The TNR program is based on neutering, and the SAZ run a program that allows humans with low income to neuter their companion cats for free. Their main reason for promoting neutering is reducing cat suffering. They rescue hundreds of stray kittens every year, many of whom are ill, and argue that shelters are full of cats who deserve to be adopted. Furthermore, intact males often fight-in cities, their territories often overlap-and it could be argued that females are better off if they are not constantly pregnant or with kittens.

Under current circumstances the SAZ's neutering programs can indeed probably be defended for the simple reason that they do reduce cat suffering in cities. There is however a more principal question of whether or not humans are ethically allowed to intervene in cats' lives and bodies in this way. This more principal question of whether humans have a right, or even a duty, to neuter cats deserves more space than I have here (see also Donaldson and Kymlicka 2011; Palmer 2013; compare 
Narayanan 2017; Srinivasan 2013). It is however interesting to note that in the case of euthanasia and neutering the SAZ never mention what the cats want, or discuss whether or not this is problematic with regard to their bodily integrity, but instead simply assume that humans know best and are allowed to intervene.

\subsubsection{Stray Cat Rights}

These tensions bring us to the question of stray cat rights. The SAZ do not advocate for universal cat rights, but they do argue for specific kinds of legislation in relation to stray cats, for example in discussions with the city council and the province, and they promote what they see as good cat-human relations through their (social) media channels. Even though they do not use the language of rights or justice-they will speak of belonging, care, or being kind instead-, their underlying ideas correspond with Sue Donaldson and Will Kymlicka's (2011) views about denizenship rights for liminal animals.

Donaldson and Kymlicka use a citizenship approach to conceptualize the rights of different nonhuman animal communities, based on their relations to human political communities. Domesticated animals are conceptualized as citizens, who form interspecies communities with humans. Wild animals are sovereign communities, who prefer to stay away from humans and who are capable of taking care of themselves. Not all animals are wild or domesticated, and for those in between, Donaldson and Kymlicka introduce a third category. Liminal animals do not desire close relations with humans, but they do seek out human settlements for safety, shelter or food, and can have different types of interactions with humans. While most SAZ cats can indeed be seen as liminal, their relations with humans vary. Some street cats are domestic cats, who after a few days or weeks, or even hours, remember how nice it was to live inside a house. Others are feral and show a strong desire to get away from humans; they will try to escape and fight for their freedom if necessary. Between these poles we find shy cats, cats who after months of attention suddenly decide to try to trust humans, cats who usually like humans but remain unpredictable in their behaviour and therefore cannot be adopted, and many others.

According to Donaldson and Kymlicka (2011, Chapter 3), the different relations between groups of human and nonhuman animals are connected to different sets of rights. Liminal animals should, in addition to the basic negative rights all nonhuman animals should have, be awarded denizenship rights. These are the right not to be stereotyped negatively, to participate in reciprocal relations, and the right to a habitat. These three rights capture what the SAZ advocate for. The SAZ have influenced public opinion of stray cats and continues to do so; in the 1990s, they were seen as pests and now the image humans have of them is much more positive. Promoting better cat-human relations, based on reciprocity and mutual consent, in cat-human households and in cities, is also one of the key aims of the SAZ. This is interconnected with arguing for the cats' right to a habitat: the SAZ argue that the city is their home too. 


\subsubsection{Democratic Agency}

One of the key features of Donaldson and Kymlicka's theory is their focus on political animal agency. Wild and liminal animals express political agency in different ways, for example through resisting oppression or leaving a certain territory. Domesticated nonhuman animals exercise democratic agency in relation to humans. They should not only be the recipients of rights or citizenship, but should be seen as political agents who co-shape communities, and whose voices should be taken into account in taking political decisions.

More specifically, they develop an account of 'dependent agency' in the case of domesticated animal citizenship. They distinguish three necessary features of exercising democratic agency, which in their opinion also apply to domesticated animals: the possibility of having and expressing a subjective good, the capacity to comply with social norms through relationships, and the capacity to participate in shaping the terms of interaction $(2011,104)$. To further conceptualize this, they turn to recent work in disability theory, and investigate parallels with theories that focus on how humans with severe mental disabilities can exercise agency through relationships that are based on trust. Exercising this dependent agency would, in the case of domesticated animals, mean that they communicate their standpoints to humans they know well and trust, and who know them well, who then communicate these to other humans. Domesticated animals have a right to be represented socially and politically through this form of interaction.

At the SAZ cats and humans exercise agency in different ways and to different degrees, and can depend on other cats and humans in a multitude of ways. Some cats and some humans live their lives without much help from others and prefer distance from them; others need more care, or prefer close relations. Politically, relations also do not follow the species line neatly. In the model that Donaldson and Kymlicka propose, the nonhuman companions depend on humans for social and political representation. At the SAZ humans speak up for the cats in official contexts, yet many humans at the SAZ also cannot or do not want to express themselves politically in this way. Furthermore, the cats act politically in other ways: they claim and defend their territories, resist captivity, vote with their feet, or cooperate with humans. While these acts differ from human political acts, they are meaningful and may have further political effects (see Meijer 2019 for a longer discussion on animal resistance).

\subsection{Cat-Human Relations at the $\mathrm{SAZ}$ as a Model for Future Interactions}

The SAZ's approach to stray cats can perhaps best be described as pragmatic. While they take seriously cat agency and subjectivity in many contexts, they restrict it at other points, as I discussed in relation to euthanasia and neutering. Furthermore, in 
ethical judgments they focus solely on cats and not on the wider environment. They feed the cats animal products, such as meat and fish,,${ }^{5}$ and do not consider the impact of cat colonies on other liminal animals, such as rodents or songbirds.

While the first issue can be solved by feeding the cats vegan diets, the second question is more difficult to answer. Thinking about sharing communities and cities with cats raises the question of intervention in their predation behaviour (Donaldson and Kymlicka 2011; Palmer 2013), since individual animals and populations may suffer from their presence. In some places stray cats are seen and welcomed as rural working animals, providing 'rodent control' (Van Patter and Hovorka 2018), while in other places there is growing public concern over their impacts on songbirds (ibid.). This latter concern is often interconnected with a discourse and world view that relies on a distinction between nature and culture, and sees feral cats as intruders who are not native to certain areas and do not belong there. Taking issue with cats who kill songbirds but not minding them killing mice and rats is furthermore speciesist. While the question of predation is an important ethical question to consider in living with companion cats, and in supporting stray or feral cats, simply blaming them for the loss of wildlife is too easy. More empirical research is needed, into the relation between feeding cats and their hunting behaviours, human influence on wildlife-for example with regard to the effect of pesticides on insects and birds-, and differences in hunting and killing behaviours of companion cats and feral cats. More research into the moral and political standing of liminal animals is also needed, and this does not just apply to cats, but also rats, mice and birds.

While there are ethical and political challenges with regard to the SAZ's policies and practices, certain aspects of their work can serve as an inspiration for developing new relations with other animals. As a conclusion to this paper I will discuss these in three areas: forming ecologies of care, sharing the city, and interspecies resistance practices.

\subsubsection{Ecologies of Care}

Relations between humans and groups of liminal animals are often framed in terms of conflict. Humans usually see themselves as the dominant party, both in terms of rationality and of power. As we saw, the SAZ problematizes assumptions about power relations between humans and cats, and humans' right to space. While humans make certain decisions, cats know what is best-for them or the human opposite them-in other cases, and this wisdom needs to be recognized. Instead of focusing on eradicating city cats, or establishing stronger borders between cat colonies and humans, they accept that interactions and relations are inevitable, and do not aim to domesticate all cats. They work towards creating better relations, offer care where needed, and recognize that care goes two ways: helping cats can help humans. In

\footnotetext{
${ }^{5}$ Many volunteers also eat animals, though this is slowly changing because of some vegan volunteers who are creating awareness.
} 
this way, the SAZ not only challenges the epistemic dichotomy between humans and other animals, but also offer another framework, one of care and not conflict.

Throughout the city of Amsterdam we find different networks of care in relation to stray cats: between cats, cats and humans, colonies and caretakers, socialized cats and volunteers, between different volunteers, between passers-by and cats in need. This is not always in perfect harmony: conflicts often occur. But care is not simply soft and sweet: it means taking responsibility for others also when that is difficult, and it can even involve making difficult decisions about life and death for others. Humans share cities and rural areas not only with cats, and relations and encounters with songbirds, mice, rats, seagulls, foxes and other animals are similarly often unavoidable. Focusing on care instead of conflict can be the first step for starting something new and perhaps even solving problems with co-existence (see Meijboom and Nieuwland on rats in this volume).

\subsubsection{Sharing the City}

Recent work in political philosophy (Cooke 2017; Hadley 2005; Milburn 2017) problematizes the assumption that humans automatically have all rights to the land they share with other animals, by arguing for nonhuman animal land rights, habitat rights, or territorial rights. Humans gave themselves a right to the land, but that is not the same as having a right to that land (Meijer 2019). The idea is not just that other animals belong in their habitats, have a right to their territory and should have access to the means they need to sustain their existence: it also imposes limits on human expansion, and even raises the question of giving land back to the animals who lived there in the first place (Donaldson and Kymlicka 2011).

Cities are seen as a product of human activity, and therefore as belonging to the humans who built them and not to the other animals who lived there before, or who came to live there when humans did. Jennifer Wolch (2010) sees a lack of nonhuman animals in urban theories and practices. This is related to the fact that cities are seen as human spaces, and the fact that urbanisation is based on a view of progress that favours culture over nature, which leads to exploitation of nature. To address this, she argues, we need not only to acknowledge and foster the presence of those other animals in cities, but also to build new relations with them.

Stray cats are not wild, and do not fall on the side of nature or wilderness, but are also not domesticated and living within human culture. They contest physical boundaries, by forming their own communities within city borders, often trespassing on land that belongs to individual humans and companies - they like courtyards, parks, big gardens, and industrial areas- , and symbolic borders, by invading a culturally human space (Van Patter and Hovorka 2018). Colonies have their own habits and norms, and the cats have their own maps of the city (compare Barua 2014). The cats know their habitat is theirs, even when humans do not recognize this. 
Understanding cities as places that humans share with many others may mean humans need to make more space and take a step back. This however does not have to be a sacrifice: building new relations with other animals, attending to them and engaging with them differently can instead enrich one's life and lead to a deeper sense of connection with the world around you.

\subsubsection{Interspecies Resistance as the Foundation for New Relations}

New relations are not a matter of all or nothing, and are not formed in a utopian setting far away from daily realities. They can and do begin here. The SAZ shows us alternative ways of interacting with cats, in which power relations are flexible and cat agency is recognized. Some of the SAZ practices, such as caring for a group that no one cares about, can be seen as forms of resistance in a world that disregards nonhuman animal lives.

Michel Foucault (1998, see also Wadiwel 2016) conceptualizes everyday practices that challenge power structures as forms of resistance, which is a helpful way of looking at these cat-human relations. Similar to the ecologies of care I mentioned earlier, these patterns could perhaps best be described as ecologies of resistance, in which cats and humans resist oppression. The humans working at the SAZ sometimes describe their work in terms of resistance, to indifference and hostile attitudes to cats, and they take pride in being disobedient. They also often call themselves crazy and describe themselves as being literally from the streets, and it seems as if they take pride in being like the cats.

Their struggle and resistance is not aimed at large societal reform, and their acts are at times morally inconsistent. There are also often conflicts between this organisation and other animal shelters and organisations; they fight over resources and principles. But the SAZ does manage to bring about small, and sometimes big, changes in the lives of many cats and humans, they changed how cats are viewed and treated in Amsterdam, and they are a last resort for humans and cats who have nowhere else to go. With this they offer a glimpse of new interspecies relations, co-shaped by the cats.

\section{References}

Alger, J., and S. Alger. 1997. Beyond Mead: Symbolic interaction between humans and felines. Society \& Animals 5 (1): 65-81.

Alger, J., and S. Alger. 2003. Cat culture: The social world of a cat shelter. Philadelphia, PA: Temple University Press.

Barua, M. 2014. Bio-geo-graphy: Landscape, dwelling, and the political ecology of human-elephant relations. Environment and Planning D: Society and Space 32: 915-934.

Bennett, J. 2010. Vibrant matter: A political ecology of things. Durham, UK: Duke University Press. 
Cooke, S. 2017. Animal kingdoms: On habitat rights for wild animals. Environmental Values 26 (1): $53-72$.

Donaldson, S., and W. Kymlicka. 2011. Zoopolis: A political theory of animal rights. Oxford: Oxford University Press.

Foucault, M. 1998. The will to knowledge: The history of sexuality, vol. 1. London: Penguin Books. Gruen, L. 2015. Entangled empathy: An alternative ethic for our relationships with animals. New York: Lantern Books.

Hadley, J. 2005. Non-human animal property: Reconciling environmentalism and animal rights. Journal of social philosophy 36 (3): 305-315.

Latour, B. 1993. We have never been modern. Cambridge, MA: Harvard University Press.

Meijer, E. 2019. When animals speak: Toward an interspecies democracy. New York: New York University Press.

Milburn, J. 2017. Nonhuman animals as property holders: An exploration of the Lockean Labourmixing account. Environmental Values 26 (5): 629-648.

Narayanan, Y. 2017. Street dogs at the intersection of colonialism and informality: 'Subaltern animism' as a posthuman critique of Indian cities. Environment and Planning D: Society and Space 35 (3): 475-494.

Palmer, C. 2013. Companion cats as co-citizens? Comments on Sue Donaldson's and Will Kymlicka's Zoopolis. Dialogue 52 (4): 759-767.

Srinivasan, K. 2013. The biopolitics of animal being and welfare: Dog control and care in the UK and India. Transactions of the Institute of British Geographers (1): 106-119.

Taylor, S. 2017. Beasts of burden: Animal and disability liberation. New York: The New Press.

Van Patter, L.E., and A.J. Hovorka. 2018. 'Of place' or 'of people': Exploring the animal spaces and beastly places of feral cats in southern Ontario. Social and Cultural Geography 19 (2): 275-295.

Wadiwel, D.J. 2016. Do fish resist? Cultural Studies Review 22 (1): 196.

Wolch, J. 2010. Zoöpolis. In Metamorphoses of the zoo: Animal encounter after Noah, ed. R. Acampora, 221-245. Plymouth, UK: Lexington Books.

Eva Meijer works as a postdoctoral researcher at Wageningen University (NL) in the project Anthropocene Ethics: Taking Animal Agency Seriously. She taught (animal) philosophy at the University of Amsterdam and is the chair of the Dutch study group for Animal Ethics, as well as a founding member of Minding Animals The Netherlands. Recent publications include Animal Languages (John Murray 2019) and When animals speak. Toward an Interspecies Democracy (New York University Press 2019). Meijer wrote nine books, fiction and non-fiction, that have been translated into sixteen languages.

Open Access This chapter is licensed under the terms of the Creative Commons Attribution 4.0 International License (http://creativecommons.org/licenses/by/4.0/), which permits use, sharing, adaptation, distribution and reproduction in any medium or format, as long as you give appropriate credit to the original author(s) and the source, provide a link to the Creative Commons license and indicate if changes were made.

The images or other third party material in this chapter are included in the chapter's Creative Commons license, unless indicated otherwise in a credit line to the material. If material is not included in the chapter's Creative Commons license and your intended use is not permitted by statutory regulation or exceeds the permitted use, you will need to obtain permission directly from the copyright holder.

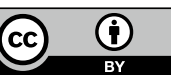

